\title{
県別新放鳥一覧
}

\section{Numbers of newly banded birds by}

\section{prefecture(1991.1 1991.12.31)}

1991年の新放鸟数について、県別に集計し一筧とした。さら に、全国で100将以上の版島となった種についてその最多放鳥 者名を付記し、放鸟数1羽の種についても版鳥者名を付記し た。使用した記号については、共同謂查者を「\&」、同数調榃 者を「ニ」とし、保謢放鸟は「ホ」とした。なお、氏名の公表 に際しては例年同様、ご本人の承諽を得ていないがご客教願い たい。

1990年と比䡈して、新放鸟数では5,583 羽の増加となった。 標譩協会で県別新放鳥一敛を作成するようになってから6年を 経過したが、毎年版鳥数の增加がみられる。これはひとえに、 バンダー全具の努力の䊅果といえる。残念なのは末だに放鳥数 が全くない県がいくつがあることである。しかし、今後、鳥類 標識闌杳に对する杜会の理解が増すにしたがってバンダーも增 え、放鳥数の空白県も解消できるのではないかと思われる。今 後のハンターの活羁に期待したい。

(担当 吉安·不本)

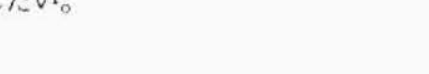

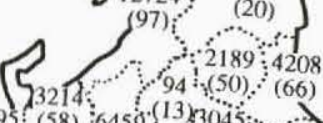
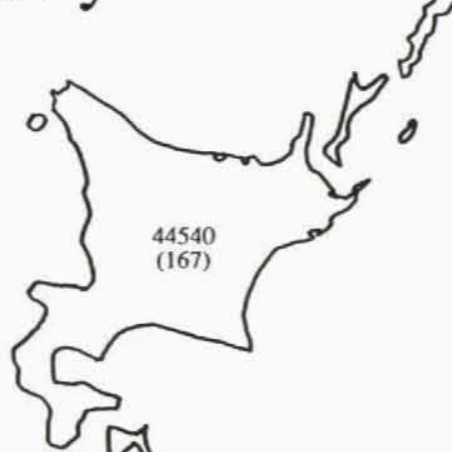

$716^{2}+10: 48522^{25455}$

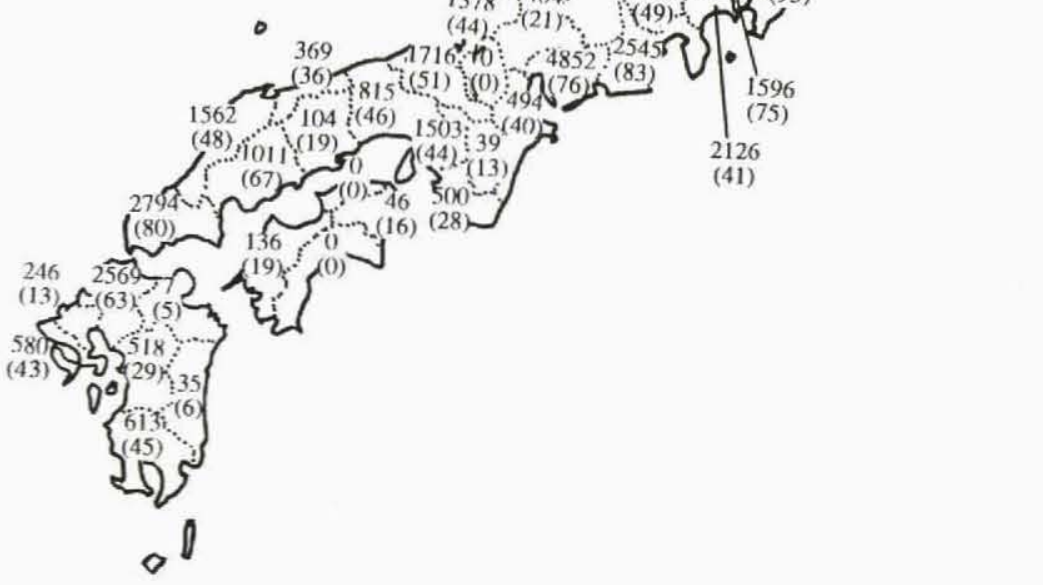

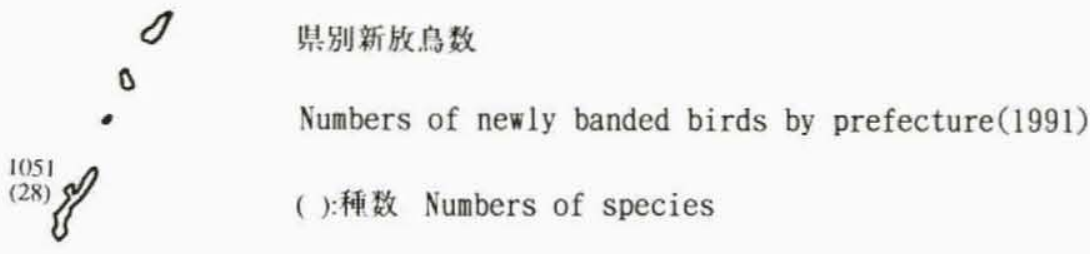




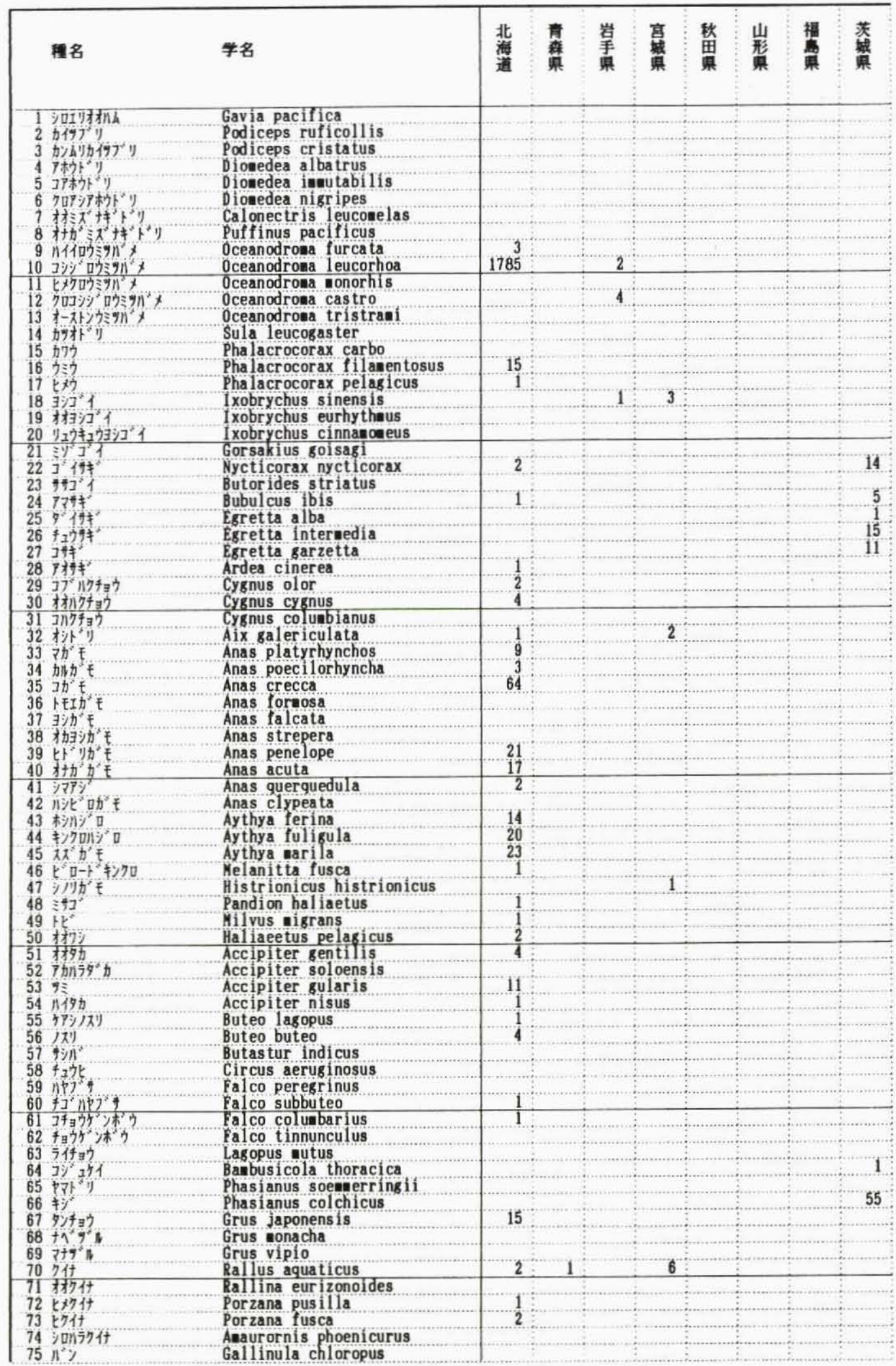

Bul1. JBBA 7, 1992 


\begin{tabular}{|c|c|c|c|c|c|c|c|c|c|c|c|c|c|c|c|c|c|}
\hline 梊 & 鷿 & 樯 & 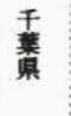 & $\begin{array}{l}\text { 香 } \\
\text { 都 }\end{array}$ & 检 & 亲 & 禽 & 硈 & 望 & 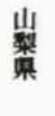 & $\begin{array}{l}\text { 長 } \\
\text { 罯 }\end{array}$ & 䉪 & 兽 & 䨒 & 重 & 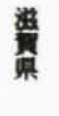 & 泉 \\
\hline & & & 2 & 1 & & 2 & & & & & 1 & & & & & & \\
\hline & & & & $\begin{array}{r}1 \\
66\end{array}$ & & & & & & & & & & & & & \\
\hline & & & & $\begin{array}{r}66 \\
9\end{array}$ & & & & & & & & & & & & & \\
\hline & & & & $\frac{261}{3}$ & & 2 & & & & & & & & & & & \\
\hline & & & & 14 & & 2 & & 101 & & & 2 & 2 & & & & & 443 \\
\hline & & & 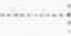 & 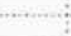 & & & & & & & & & & & & & \\
\hline & & $\ldots \ldots$ & $\ldots$ & $\frac{1}{3}$ & & 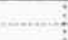 & & $\ldots$ & $\ldots$ & $\ldots$ & $\ldots$ & $\ldots$ & -1. & $\ldots+\ldots$ & & & 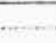 \\
\hline & & & $\ldots \ldots$ & 16 & & & & $\ldots$ & & & & & $1-\ldots$ & $-\cdots$ & & & \\
\hline & & & 1 & $\begin{array}{l}62 \\
60\end{array}$ & & & & 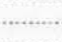 & & & & & 50 & $\ldots$ & & & \\
\hline & & & & & & 2 & & $\ldots$ & & & & & . & $\ldots$ & & & \\
\hline & & 38 & 16 & 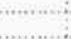 & 4 & 2 & & 1 & & & & $\ldots$ & $\ldots-1$ & $\ldots . .$. & & $\ldots$ & \\
\hline & & & & & & & & & & & & 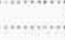 & $\ldots$ & $\ldots$ & $\ldots$ & $\ldots$ & $\cdots$ \\
\hline & & & & & & & & & & & & & & & & & \\
\hline & & & 8 & & & 7 & & 4 & & & 12. & & 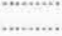 & & & & $\ldots$ \\
\hline & & & 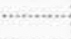 & & & 1 & & 1 & & & 11 & ..... & $\ldots$ & & & & $\ldots$ \\
\hline & & & $\ldots \ldots$ & $\ldots$ & & $\ldots$ & & $\ldots$ & $\ldots$ & & 1 & $\ldots$ & $\ldots$ & & 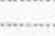 & & $\ldots$ \\
\hline & & & 2 & 1 & & & & 2 & & & $\frac{1}{3}$ & & 1 & & 1 & & $\ldots$ \\
\hline & & $\ldots . . .$. & 1 & & & 1 & & 2 & & & 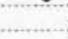 & & & & & & \\
\hline$\ldots$ & & & 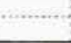 & & & & & 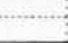 & & & $\ldots \ldots$ & $\ldots \ldots$ & 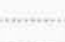 & & 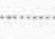 & & $\cdots$ \\
\hline & & $\ldots .$. & $\ldots \ldots$ & $\ldots$ & 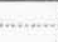 & & $\ldots$ & $\ldots \ldots$ & & 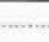 & 1 & 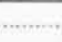 & 24 & $\ldots$ & $\ldots \ldots$ & $\ldots$ & 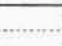 \\
\hline & & 233 & & & & 6 & & & & & 3 & & 64 & & & & 1 \\
\hline 1 & & & 16 & 8 & & 1 & & 14 & & & 1 & & 4 & & & & \\
\hline & & $\begin{array}{l}3 \\
2\end{array}$ & $\begin{array}{l}5 \\
1\end{array}$ & & & & & 1 & & & 10 & & & 51 & & & \\
\hline & & 3 & & & & & & & & & & & $\ldots$ & $\cdots$ & . & & \\
\hline & & 5 & 84 & & & & & & & & $1^{2}$ & & 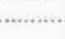 & $\ldots \ldots$ & & & \\
\hline & & 912 & 1189 & 1 & & & & & & & 8 & & & 166 & & & \\
\hline & & 39 & 7 & & & & & $\ldots$ & & & 3 & & $\ldots$ & $\cdots$ & 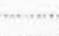 & & \\
\hline & & 289 & 155 & 1 & & & & 1 & & & 1 & & 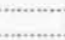 & 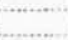 & & & \\
\hline & & 80 & 57 & & & & & & & & & $\cdots$ & & & & & \\
\hline & & $+m$ & & & & & & ........... & & & & & & $\mathrm{r}$ & & & \\
\hline & ..... & $\ldots .$. & ..... & $\ldots$ & & . & & $\ldots$ & & & $\ldots$ & & & $\ldots$ & & & \\
\hline & & $\ldots . .$. & $\ldots$ & $\ldots$ & & 9 & & 16 & & & 34 & & & 2 & & & \\
\hline$\ldots$ & 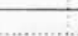 & 1 & 2 & 4 & & 3 & & 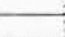 & & & & & . & 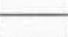 & & & \\
\hline & I & & & & & & & & & & & & $\cdots$ & & & & \\
\hline & & & 1 & & & $\ldots$ & & 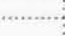 & & & & $\ldots$ & 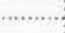 & 3 & & & \\
\hline & & & & & & $\ldots$ & & & & & $\ldots$ & $\ldots$ & ㄱ. & …… & $\ldots$ & & $\cdots$ \\
\hline & & 1 & 2 & & & & & 1 & & & 2 & & & $\ldots$ & & & \\
\hline & & & $\ldots \ldots$ & & & & 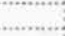 & 18 & & & & $\ldots$ & . & 8 & & & $\cdots$ \\
\hline & 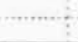 & . & 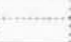 & & & 1 & & 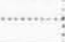 & & & & 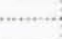 & $\ldots$ & & & & \\
\hline & & 1 & & & & 10 & 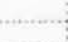 & $\ldots$. & & & & 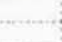 & $\ldots \ldots$ & 1 & & & $\ldots$ \\
\hline & & & & & & & 15 & & & & & & & & & & \\
\hline & & & & 1 & & & & & & & & $\ldots .$. & 3 & & & & $\ldots$ \\
\hline 15 & & $\ldots .$. & 1 & & & 4 & & 8 & & & & 1 & & & $\ldots$ & & 2 \\
\hline & & & & & & & & 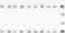 & & & 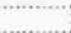 & & & . & 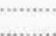 & 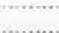 & 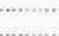 \\
\hline & & $\ldots$ & 1 & & & & & 1 & & & 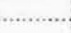 & & & 1 & & & \\
\hline & & . & & & & & & 1 & & & & & & 1 & & & \\
\hline & & 1 & & & & & & 1 & & & & & & $\ldots \ldots$ & & & ….... \\
\hline & & & & & & & & & & & & & & & & & \\
\hline & & & 3 & & & & & & & & & & & 1 & & & 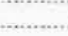 \\
\hline
\end{tabular}

日本鳥類標識協会誌 7, 1992 


\begin{tabular}{|c|c|c|c|c|c|c|c|c|c|c|}
\hline 種名 & 学名 & $\begin{array}{l}\text { 北海 } \\
\text { 道 }\end{array}$ & $\begin{array}{l}\text { 霖 } \\
\text { 想 }\end{array}$ & $\begin{array}{l}\text { 岩 } \\
\text { 寨 }\end{array}$ & 蒚 & $\begin{array}{l}\text { 箅 } \\
\text { 県 }\end{array}$ & 形 & $\begin{array}{l}\text { 聂 } \\
\text { 皿 }\end{array}$ & 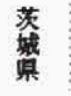 & 禁 \\
\hline 76 材 & Fulica atra & & & & & & & & & \\
\hline 77 97 & Rostratula benghalensis & & & & & & & & 1 & \\
\hline 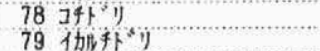 & & & & & & & & & & \\
\hline 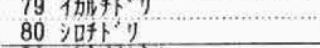 & Charadrius alexandrinus & & & & 1 & & & & 5 & \\
\hline 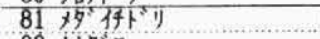 & Charadrius mongolus & 8 & & & & & & & & \\
\hline $824+5$ & Pluvialis doninica & 1. & & & & & & & & \\
\hline $\begin{array}{l}83 \% \text { 他 } \\
84 \%\end{array}$ & $\begin{array}{l}\text { Pluvialis squatarola } \\
\text { Microsarcops cinereus }\end{array}$ & & & & & & & & & \\
\hline 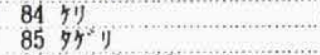 & $\begin{array}{l}\text { Microsarcops cinereus } \\
\text { Vanellus vanellus }\end{array}$ & & & & & & & & & \\
\hline $86 \neq a b \%$ f & Arenaria interpres & 2 & & & & & & & & \\
\hline $87+5 *$ & Calidris ruficolis is & $16 \overline{6}$ & 13 & & 4 & & & & & \\
\hline $88 \mathrm{kn}$ 才洋 & Calidris ninutilla & ii & & & 1 & & & & & \\
\hline $893 x \ni$ 洋 & Calidris acuinata & & & & & & & & & \\
\hline 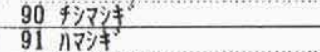 & $\begin{array}{l}\text { Calidris ptilocnenis } \\
\text { Calidris alpina }\end{array}$ & 14 & & & & & & & & \\
\hline 92 *n & Calidris ferrug inea & 1 & & & & & & & & \\
\hline 93 j才湔 & Calidris canutus & & & & & & & & & \\
\hline 94 枆洋 & Calidris tenuirostris & 2 & & & & & & & & \\
\hline 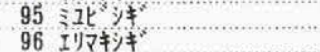 & $\begin{array}{l}\text { Crocethia alba } \\
\text { Philoaachus pugnax }\end{array}$ & & & & & & & & & \\
\hline 97 打1 & Líicola falcinellus & 1 & 1 & & 1 & & & & & \\
\hline 98 7 万P洋 & Tringa totanus & & & & & & & & & \\
\hline 993777 洋 & Tringa stagnatilis & 1 & & & & & & & & \\
\hline 100 狈洋 & Tringa nebularia & 4 & & & & & & & & \\
\hline 1017 H洋 & Tringa ochropus & & & & 2 & & & & .......... & \\
\hline 102 多 & $\begin{array}{l}\text { Tringa slareola } \\
\text { Tringa incana }\end{array}$ & 3 & & & & & & & 1 & \\
\hline 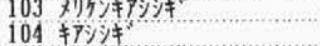 & $\begin{array}{l}\text { Tringa incana } \\
\text { Tringa brevipes }\end{array}$ & 59 & & & 5 & & & & & \\
\hline 105 似的 & tringa hypoleucos & 10 & & & & & & & & \\
\hline 106 以啡 & Xenus cinereus & 1 & & & 2 & & & & & \\
\hline & Linosa linosa & & & & & & & & & \\
\hline 108 打贸海 & Linosa lapponica... & 6 & & & 4 & & & & $\ldots$ & \\
\hline 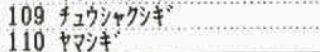 & $\begin{array}{l}\text { Numen ius phaeopus } \\
\text { Scolopax rusticola }\end{array}$ & $\begin{array}{r}9 \\
10\end{array}$ & & & & & 1 & & & \\
\hline $111.775779 F^{\prime}$ & Scolopax nira & & & & & & & & & \\
\hline 112 汼 & Gallinago gallínago & 25 & & & 8. & & & & & \\
\hline 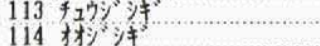 & $\begin{array}{l}\text { Gallinago esala } \\
\text { Galilinago hardwickil }\end{array}$ & 16 & & & 11 & & & & & \\
\hline 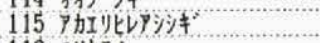 & Phalaropus loba tus & 6 & & & 1 & & & & & \\
\hline 116 IJthx & Larus ridibundus & & & & & & & & & \\
\hline 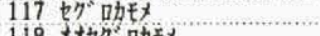 & Larus argentatus & & & & & & & & & \\
\hline 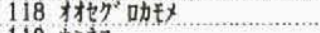 & Larus schistisagus & 1544 & 32 & & & & & & & \\
\hline 119 和 & Larus crassirostris & 884 & 2179 & & & & & & & \\
\hline 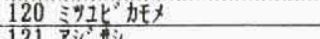 & Larus tridactylus & 108 & & & & & & & & \\
\hline 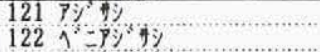 & $\begin{array}{l}\text { Sterna hirundo } \\
\text { Sterna dougalli }\end{array}$ & 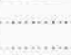 & & & & & & & & \\
\hline 123 IUग & Sterna sunatrana & & & & & & & & & \\
\hline 124 ₹ $507 \%$ & $\begin{array}{l}\text { Sterna anaethetus } \\
\text { Sterng albifrons }\end{array}$ & & & & & & & & 87 & \\
\hline & $\begin{array}{l}\text { Sterna albifrons } \\
\text { A }\end{array}$ & & & & & & & & & \\
\hline 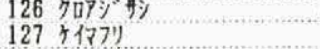 & $\begin{array}{l}\text { Anous stolidus } \\
\text { Cepphus carbo }\end{array}$ & 1 & & & & & & & & \\
\hline 128 क $32 x \times \ldots$ & Synthliboranphus antiquus & & & & & & & & & \\
\hline 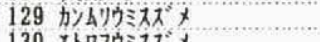 & Synthliboramphus wuizusuae & & & & & & & & & \\
\hline 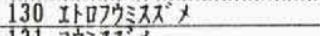 & Aethia cristatella & 1 & & & & & & & & \\
\hline 131 JSI2X & Aethia pusilla & 169 & & & & & & & & \\
\hline 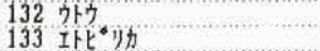 & $\begin{array}{l}\text { Cerorhinca mocerata } \\
\text { Lunda cirrhata }\end{array}$ & $\begin{array}{r}109 \\
2\end{array}$ & & & & & ....... & & 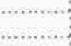 & \\
\hline $134 \sinh ^{3}$ ? & Coluaba janthina & & & & & & & & & \\
\hline $135 ; 5] n^{3}$ & Streptopelia d & & & & & & & & & \\
\hline $136 \neq F^{n}$ & elia orientalis & 34 & & & & & & & 16 & \\
\hline $137 \neq 116$ & Chalcophaps indica & & & & & & & & & \\
\hline 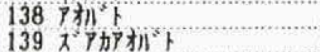 & $\begin{array}{l}\text { Sphenurus sieboldii } \\
\text { Sphenurus fornosae }\end{array}$ & 1 & & & & & & & & \\
\hline $140 \hat{y}^{2} 21 f$ & Cuculus fuga & 1 & & & & & & & & \\
\hline 141 म幺丁? & Cuculus canorus & 9 & & & & & 1 & & & \\
\hline 142 9\% y & Cuculus saturatus & 1 & & & & & & & 1 & \\
\hline 143 朴列 & Cuculus pollocephalus & & & & & & & & & \\
\hline \$קרמ & Ketupa blakistoni & 4 & & & & & & & & \\
\hline $145157 \times 3$ & Asio otus & 1 & & & & & & & 1 & \\
\hline & Asio flanneus & & & & & & & & & \\
\hline & Otus scops & $\ldots 11$ & & & & & & & & \\
\hline & otus bakkanoena. & 30 & & & & & & & & \\
\hline & Ninox scutulata. & & & & & & 2 & & & \\
\hline סל7 150 & Strix uralensis & & & & & & & & & \\
\hline
\end{tabular}

Bull. JBBA 7, 1992 


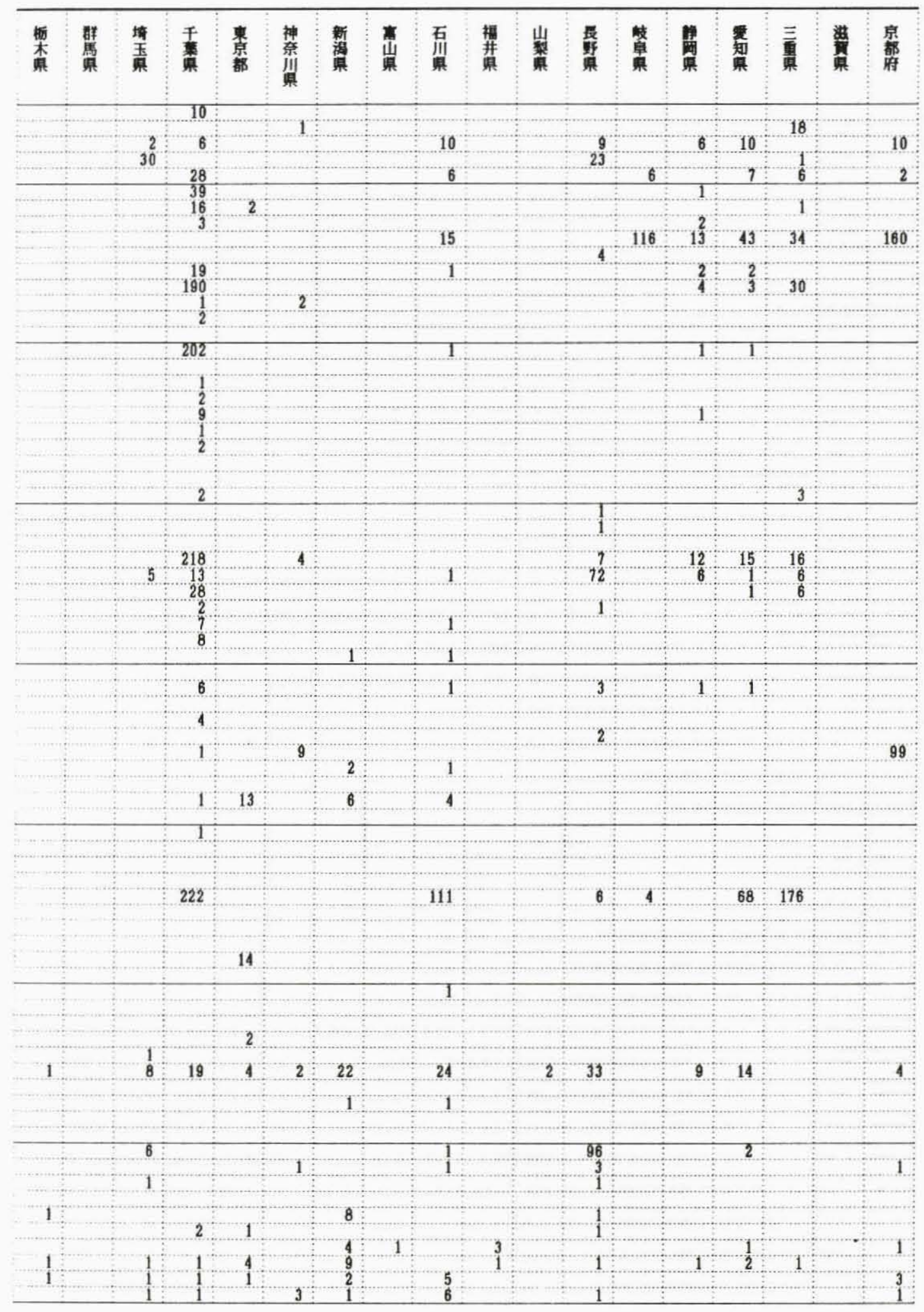




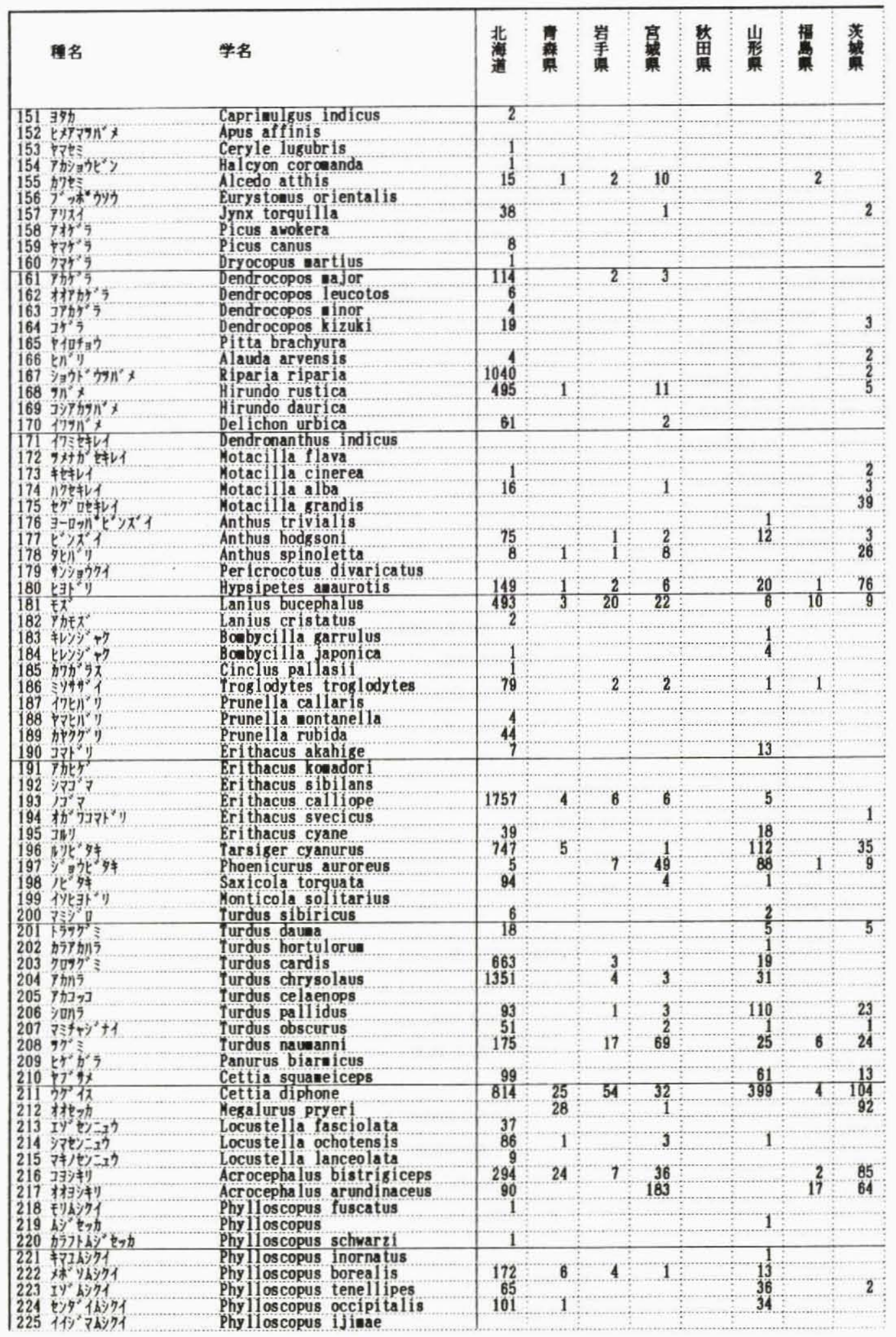




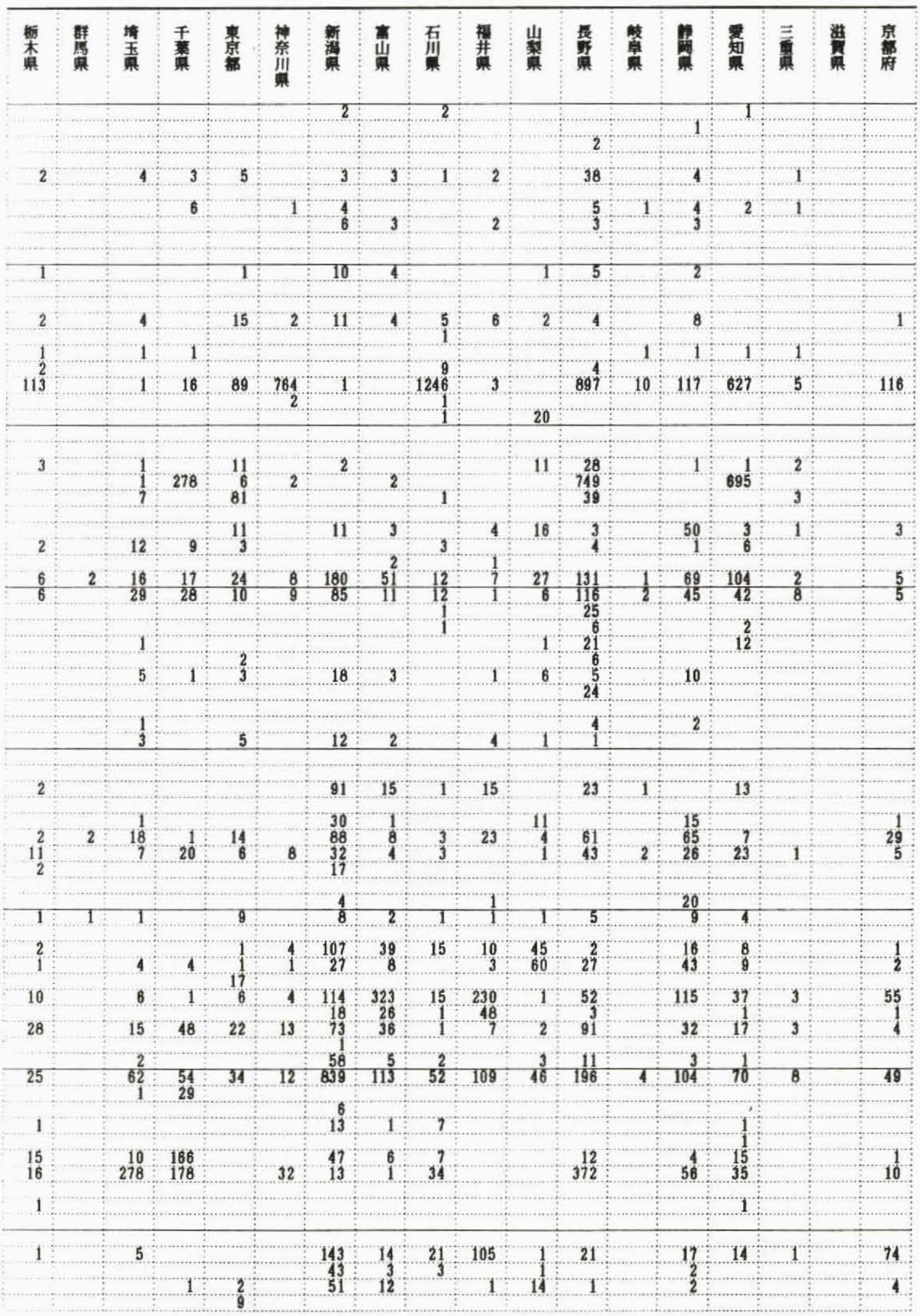




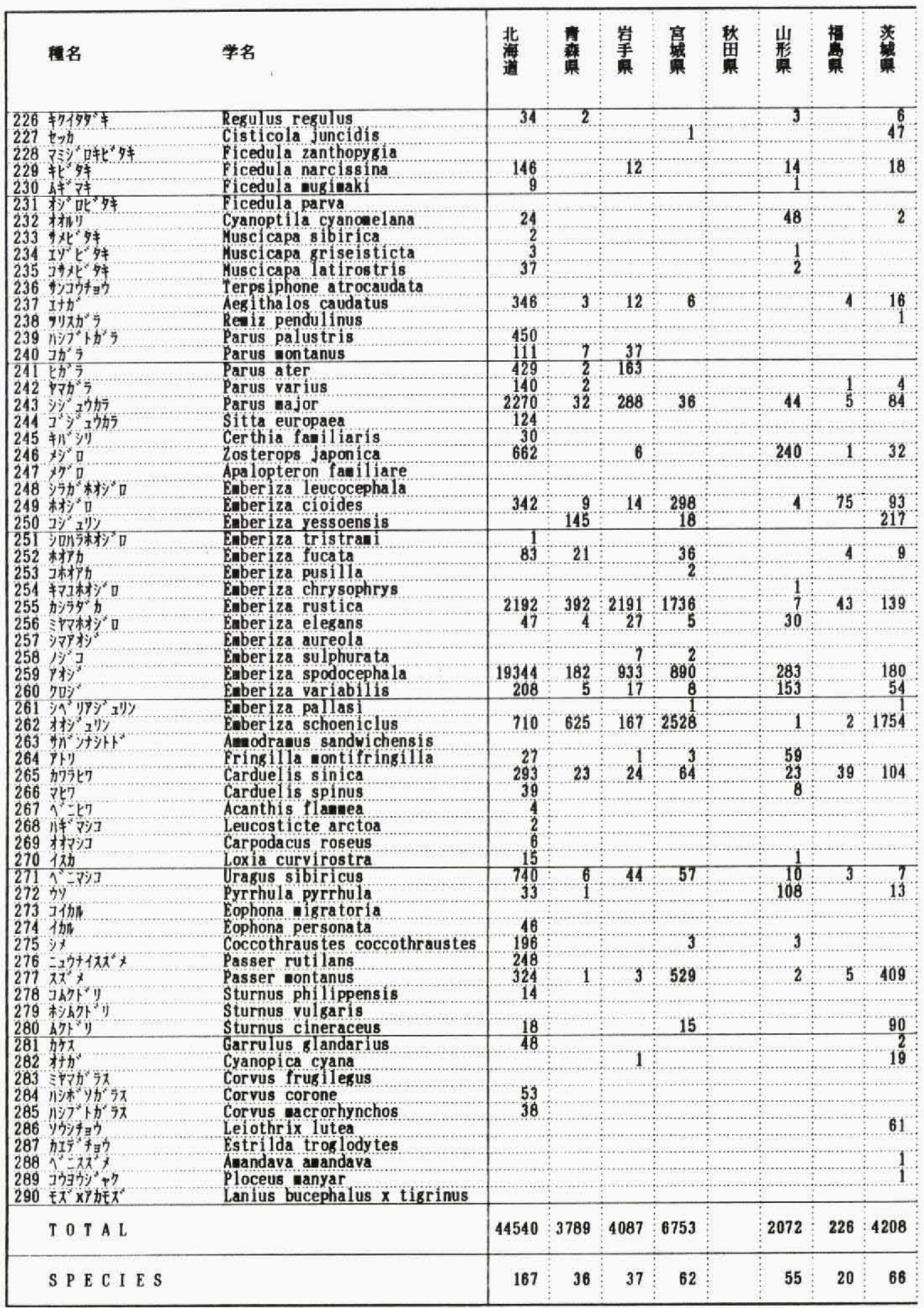




\begin{tabular}{|c|c|c|c|c|c|c|c|c|c|c|c|c|c|c|c|c|c|}
\hline 柇 & $\begin{array}{l}\text { 臂 } \\
\text { 罩 }\end{array}$ & $\begin{array}{l}\text { 境 } \\
\text { 盲 }\end{array}$ & $\begin{array}{l}\text { 委 } \\
\text { 集 }\end{array}$ & $\begin{array}{l}\text { 香 } \\
\text { 都 }\end{array}$ & $\begin{array}{l}\text { 筥 } \\
\text { 监 }\end{array}$ & 亲 & 筧 & 䂞 & $\begin{array}{l}\text { 楂 } \\
\text { 與 }\end{array}$ & 峲 & 長 & 䈇 & 前 & 零 & 董 & 灌 & 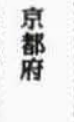 \\
\hline 7 & & 18 & 78 & 2 & 5 & 37 & 3 & $\begin{array}{l}1 \\
1\end{array}$ & 1 & 2 & 3 & & 27. & 145 & & & 1 \\
\hline & & & 6 & & & $\begin{array}{r}17 \\
5\end{array}$ & $\begin{array}{r}14 \\
4 \\
\end{array}$ & 5 & $\begin{array}{r}18 \\
2 \\
\end{array}$ & 51 & $\begin{array}{r}3 \\
1 \\
\end{array}$ & & 19 & 16 & 4 & & 14 \\
\hline & & 1 & & & & 63 & 9 & 5 & 1 & 10 & 3 & & 4 & 8 & & & 1 \\
\hline & & 1 & & 1 & & $\begin{array}{r}2 \\
26 \\
2\end{array}$ & 1 & & & 4 & & $\ldots$ & . & $\ldots$ & 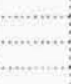 & & ..................... \\
\hline 1 & 22 & 12 & 3. & 5 & 4 & 15 & 20 & $\begin{array}{r}2 \\
7\end{array}$ & 24 & 12 & 92 & 1 & $\begin{array}{r}7 \\
58 \\
\quad 22\end{array}$ & $\begin{array}{r}4 \\
117\end{array}$ & $\begin{array}{r}1 \\
5\end{array}$ & & 18 \\
\hline 26 & $\begin{array}{r}6 \\
20 \\
27\end{array}$ & $\begin{array}{r}9 \\
17 \\
40\end{array}$ & 4 & $\begin{array}{r}6 \\
11 \\
94\end{array}$ & $\begin{array}{r}26 \\
446 \\
\end{array}$ & $\begin{array}{r}40 \\
24 \\
1486\end{array}$ & $\begin{array}{r}3 \\
8 \\
7 \\
90 \\
2\end{array}$ & $\begin{array}{r}4 \\
28 \\
\end{array}$ & $\begin{array}{r}5 \\
7 \\
10 \\
44\end{array}$ & $\begin{array}{r}55 \\
48 \\
3 \\
118 \\
1\end{array}$ & $\begin{array}{r}14 \\
89 \\
8 \\
130 \\
6\end{array}$ & 1 & $\begin{array}{r}33 \\
76 \\
73 \\
133 \\
4\end{array}$ & $\begin{array}{l}2 \\
2\end{array}$ & $\ldots$ & & $\begin{array}{r}1 \\
17 \\
\end{array}$ \\
\hline & 2 & 19 & & $\begin{array}{r}83 \\
5 \\
5\end{array}$ & 22 & 1556 & 263 & 12 & 30 & 31 & 17 & 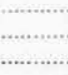 & 155 & 61 & 5 & & 256 \\
\hline $\begin{array}{r}67 \\
3\end{array}$ & & $\begin{array}{r}65 \\
2\end{array}$ & $\begin{array}{r}51 \\
141 \\
\end{array}$ & 86 & 24 & $\begin{array}{r}147 \\
5 \\
\end{array}$ & 45 & 22 & 5 & 29 & $\begin{array}{r}206 \\
2\end{array}$ & 6 & $\begin{array}{l}45 \\
12 \\
\end{array}$ & $\begin{array}{r}37 \\
4\end{array}$ & 8 & & 8 \\
\hline 2 & & 4 & 5 & & 4 & 55 & & $\begin{array}{c}1 \\
1\end{array}$ & 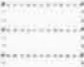 & & 2 & $\ldots$. & $\begin{array}{l}8 \\
1\end{array}$ & $\begin{array}{r}2 \\
2\end{array}$ & & & .......... \\
\hline $\begin{array}{r}704 \\
1\end{array}$ & 4 & 53 & 48 & $\frac{11}{2}$ & $\begin{array}{r}19 \\
1\end{array}$ & $\begin{array}{r}1715 \\
51 \\
\end{array}$ & $\begin{array}{r}983 \\
21\end{array}$ & $\begin{array}{r}255 \\
6\end{array}$ & $\begin{array}{r}126 \\
27\end{array}$ & $\begin{array}{r}115 \\
6\end{array}$ & $\begin{array}{r}497 \\
23\end{array}$ & 6 & $\begin{array}{r}116 \\
5\end{array}$ & 116 & $\begin{array}{r}16 \\
1\end{array}$ & & $\begin{array}{l}78 \\
21\end{array}$ \\
\hline $\begin{array}{r}114 \\
4\end{array}$ & & $\begin{array}{r}124 \\
9 \\
\end{array}$ & $\begin{array}{r}62 \\
1\end{array}$ & $\begin{array}{c}58 \\
4 \\
\end{array}$ & $\begin{array}{r}64 \\
3 \\
\end{array}$ & \begin{tabular}{r}
76 \\
1878 \\
\hdashline$\quad 93$ \\
\end{tabular} & $\begin{array}{r}2 \\
672 \\
78 \\
\end{array}$ & 27 & $\begin{array}{r}438 \\
36 \\
\end{array}$ & $\begin{array}{r}6 \\
127 \\
1\end{array}$ & $\begin{array}{r}6 \\
848 \\
9 \\
\end{array}$ & 231 & $\begin{array}{r}5 \\
145 \\
64\end{array}$ & $\begin{array}{r}1 \\
555 \\
15 \\
\end{array}$ & $\begin{array}{r}30 \\
5 \\
\end{array}$ & & $\begin{array}{l}69 \\
23 \\
\end{array}$ \\
\hline 299 & $\ldots$ & 166 & 964 & 63 & 4 & 1853 & 118 & 241 & $\ldots$ & ....... & 368 & & 301 & 1497 & 16 & & 10 \\
\hline $\begin{array}{r}3 \\
145 \\
3\end{array}$ & 5 & $\begin{array}{r}1 \\
32\end{array}$ & 108 & $\begin{array}{r}3 \\
44 \\
13\end{array}$ & 36 & $\begin{array}{r}68 \\
406 \\
198\end{array}$ & $\begin{array}{r}\frac{1}{18} \\
21\end{array}$ & $\begin{array}{l}4 \\
3 \\
3\end{array}$ & 5 & $\begin{array}{r}2 \\
9\end{array}$ & $\begin{array}{l}20 \\
76 \\
14\end{array}$ & & 14 & 13 & 6 & & 10 \\
\hline & . & & & & .... & 1 & & 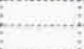 & & $\ldots$ & & & ........ & & & & $\ldots$ \\
\hline & & $\ldots$ & $\ldots$ & $\ldots \ldots$ & $\ldots$ & 68 & & & & $\ldots \ldots$. & $\cdots$ & $\ldots \ldots$ & 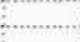 & .....: & 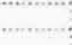 & . & 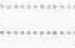 \\
\hline $\begin{array}{r}24 \\
8\end{array}$ & 1 & 6 & 6 & 1 & & & $\frac{11}{85}$ & 7 & 5 & $\begin{array}{l}7 \\
1\end{array}$ & $\begin{array}{r}75 \\
27\end{array}$ & 1 & $\frac{11}{6}$ & 9 & 1 & & 3 \\
\hline 6 & 1 & 26 & 1 & 2 & 1 & $\begin{array}{l}2 \\
3\end{array}$ & 7 & 1 & & 16 & $\begin{array}{l}14 \\
77\end{array}$ & & $\begin{array}{r}18 \\
8\end{array}$ & & & & $\ldots$ \\
\hline 493 & 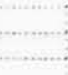 & 272 & 151 & 112 & 64 & $\begin{array}{r}305 \\
6\end{array}$ & 6 & 100 & & 10 & $\begin{array}{l}127 \\
123\end{array}$ & 5 & 72 & 54 & 57 & & 78 \\
\hline & & & 6 & $\frac{2}{2}$ & 511 & 13 & & 27 & & & $\frac{86}{3}$ & 2 & $\frac{1}{9}$ & 47 & & & 1 \\
\hline 3 & 1 & 4 & 7 & 1 & 2 & 4 & & 1 & & & 63 & & & & & & 1 \\
\hline & ....... & & 1 & 45 & & & & 1 & & & 9 & & & & & & ...... \\
\hline & & & 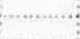 & & 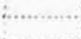 & & & & & & & & 11 & & & & $\ldots$ \\
\hline & $\ldots$ & & 1 & & & & & & & & & & 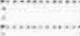 & 6 & & & \\
\hline & & & & & & & & & & & 4 & & & & & & \\
\hline 2189 & 94 & 3045 & 5137 & 1596 & 2126 & 12724 & 3214 & 2595 & 1378 & 949 & 6459 & 404 & 2454 & 4852 & 494 & & 1716 \\
\hline 50 & 13 & 76 & 93 & 75 & 41 & 97 & 58 & 90 & 44 & 49 & 110 & 21 & 83 & 76 & 40 & & 51 \\
\hline
\end{tabular}




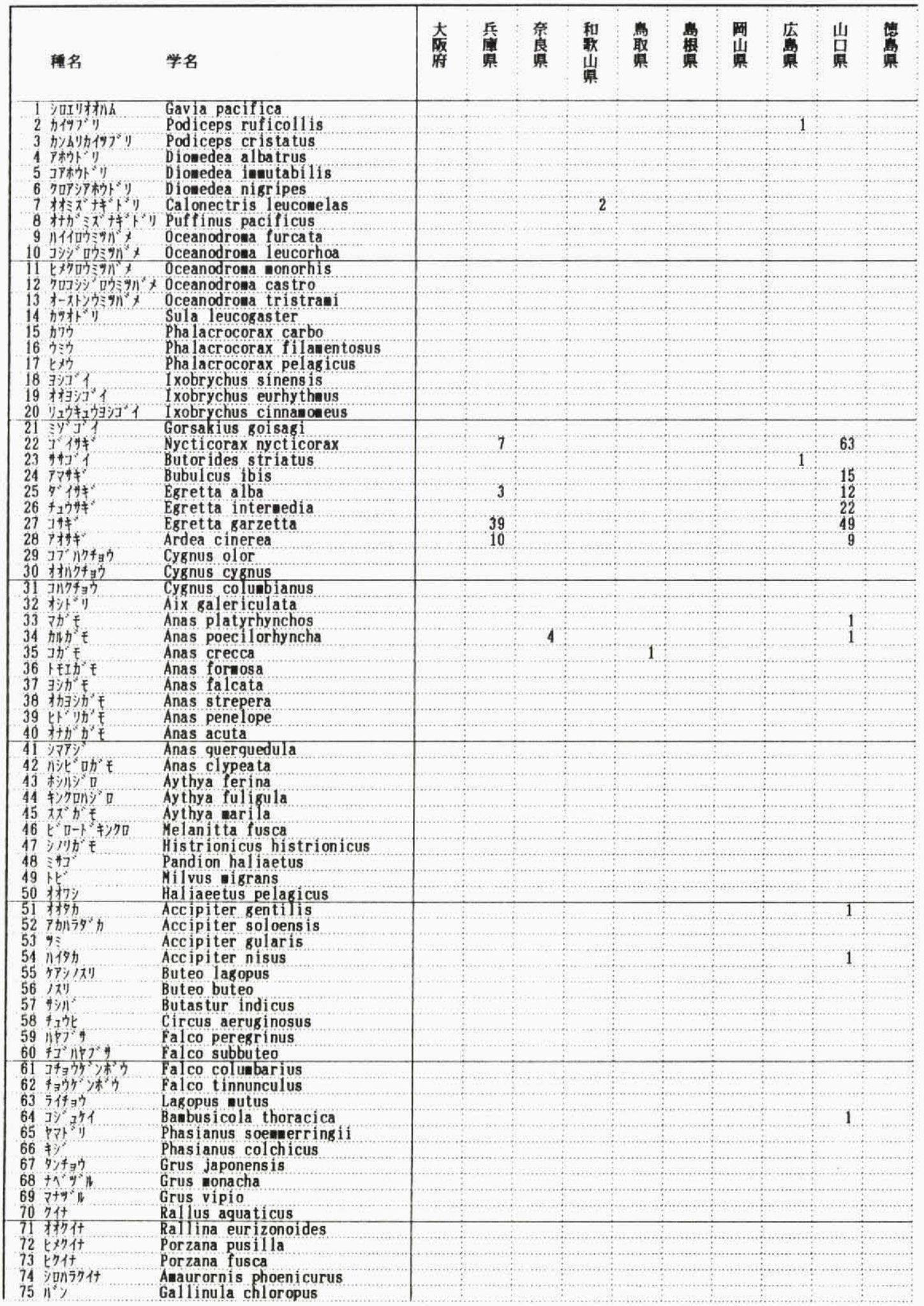

Bull. JBBA 7, 1992 


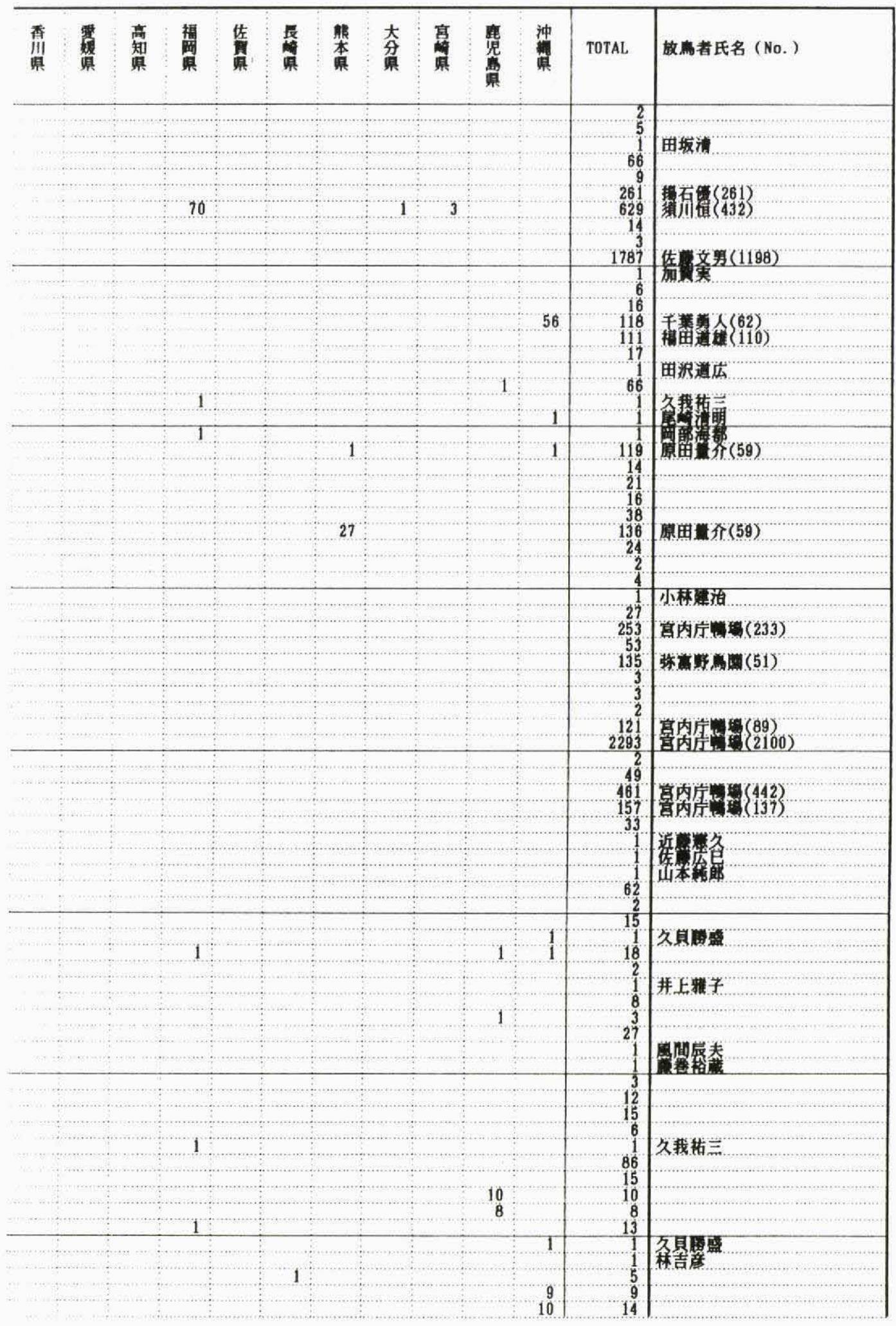




\begin{tabular}{|c|c|c|c|c|c|c|c|c|c|c|c|c|}
\hline & 種名 & 学名 & 套 & $\begin{array}{l}\text { 岳 } \\
\text { 㯒 }\end{array}$ & $\begin{array}{l}\text { 荣 } \\
\text { 良 } \\
\text { 县 }\end{array}$ & $\begin{array}{l}\text { 和 } \\
\text { 䨒 } \\
\text { 崖 }\end{array}$ & $\begin{array}{l}\text { 㱒 } \\
\text { 焣 } \\
\text { 県 }\end{array}$ & 离 & $\begin{array}{l}\text { 闻 } \\
\text { 嵔 }\end{array}$ & $\begin{array}{l}\text { 底 } \\
\text { 量 }\end{array}$ & $\begin{array}{l}\text { 山 } \\
\text { 異 }\end{array}$ & 管 \\
\hline 76 & क्राn一 & Fulica atra & & & & & & & & & & \\
\hline 77 & タาシキ & Rostratula benghalens is & & 3 & & & & & & & & \\
\hline 78 & $3+r^{2}=$ & Charadrius dubius & & 4 & & & & & & & & \\
\hline 79 & 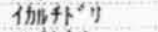 & Charadrius placidus & & 1 & & & & & & & & \\
\hline 80 & $30+r^{\prime} y$ & Charadrius alexandrinus & & & & & & & & & & \\
\hline 81 & $x x^{2} 1+r^{2}$ & Charadrius mongolus & & & & & & & & & & \\
\hline 82 & $A+\eta \mathrm{D}$ & Pluvialis doninica & & & & & 1 & & & & 1 & \\
\hline 83 & $y+1 t^{\prime} y$ & Pluvialis squatarola & & & & & & & & & & \\
\hline 84 & ril & Hicrosarcops cinereus & & 5 & & & & & & & & \\
\hline 85 & $9 x^{2} y$ & Vanellus vanellus & & & & & & & & & & \\
\hline 86 & 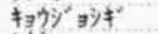 & Arenaria interpres & & & & & 1 & & & & & \\
\hline 87 & $12 \neq y$ & Calidris ruficollis & & & & & 7 & 1 & & & 10 & \\
\hline 88 & 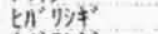 & Calidris ninutilla & & & & & & & & & & \\
\hline 89 & $3 x^{2} 5 y=$ & Calidris acuminata & & & & & & & & & & \\
\hline 90 & チシマ沛 & Calidris ptilocnewis & & & & & $\frac{1}{2}$ & & & & & \\
\hline 91 & กร特 & Calidris alpina & & & & & 2 & & & & 32 & \\
\hline 92 & ชทกマンギ & Calidris ferruginea & & & & & 1 & & & & & \\
\hline 93 & 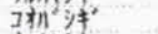 & Calidris canutus & & & & & & 3 & & & & \\
\hline 94 & $x^{2}$ 洋 & Calidris tenuirostris & & & & & & 5 & & & & \\
\hline 95 & $31 \mathrm{k}^{3} \dot{y}=$ & Crocethia alba & & & & & & 1 & & & & \\
\hline 96 & Iリフキ乡キ & Phi losachus pugnax & & & & & & & & & & \\
\hline 97 & $\neq 171$ & Livicola falcinellus & & & & & & & & & & \\
\hline 98 & P加シシキ & Tringa totanus & & & & & & & & & 1 & \\
\hline 99 & ᄀフォアシタキ & Tringa stagnatilis & & & & & & & & & & \\
\hline 100 & 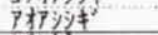 & Tringa nebularia & & & & & & 1 & & & 2 & \\
\hline 101 & 3917 & Tringa ochropus & & & & & $\overline{3}$ & & & & & \\
\hline 102 & $y+7^{3} y \neq$ & Tringa glareola & & & & & & & & & & \\
\hline 103 & $x^{114} \neq 7 \% \neq^{2}$ & Tringa incana & & & & & & & & & & \\
\hline 104 & $\neq 7 \%$ ₹ & Tringa brevipes & & & & & 1 & 2 & & & 12 & \\
\hline 105 & 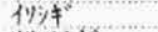 & Tringa hypoleucos & & & & & 3 & & & & 4 & \\
\hline 106 & 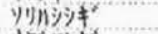 & Xenus cinereus & & & & & & & & & 30 & \\
\hline 107 & 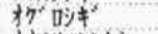 & Linosa línosa & & & & & & & & & & \\
\hline 108 & 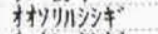 & Lieosa lapponica & & & & & & 1 & & & 3 & \\
\hline 109 & $+278+7 y \neq$ & Nunen ius phaeopus & & & & & & & & & 1 & \\
\hline 110 & $P 7 \forall \neq$ & Scolopax rusticola & & & & & & & & & & \\
\hline 111 & 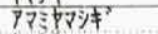 & Scolopax ilra & & & & & & & & & & \\
\hline 112 & 多泙 & Gallínago gallinago & & & & & & & & & & \\
\hline 113 & 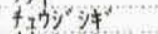 & Gallinago megala & & & & & & & & & & \\
\hline 114 & $x+y^{\prime}$ & Gallinago hardwickil & & & & & & & & & & \\
\hline 115 & 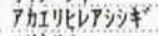 & Phalaropus lobatus & & & & & & & & & & \\
\hline 116 & Iythex & Larus ridibundus & & & & & & & & & 20 & \\
\hline 117 & to bthex & Larus argentatus & & & & & & & & & & \\
\hline 118 & 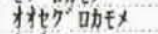 & Larus schistisagus & & & & & & & & & & \\
\hline 119 & 利 & Larus crassirostris & & & & & & & & & & \\
\hline 120 & I9I5 怔x & Larus tridactylus & & & & & & & & & & \\
\hline 121 & $7 y^{5}+4$ & Sterna hirundo & & & & & & & & & & \\
\hline 122 & $1^{2}=7 \%+3$ & Sterna dougallii & & & & & & & & & & \\
\hline 123 & $I \eta \eta \square Y \%$ & Sterna sumatrana & & & & & & & & & & \\
\hline 124 & $75 y^{\prime} \mathrm{a} 7 y^{x}+4$ & Sterna anaethetus & & & & & & & & & & \\
\hline 125 & 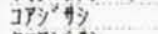 & Sterna albifrons & 1 & 21 & & & 6 & & & & & \\
\hline 126 & $707 \%$ & Anous stolidus & & & & & & & & & & \\
\hline 127 & ห位监 & Cepphus carbo & & & & & & & & & & \\
\hline 128 & $n \equiv x x^{2} \times$ & Synthliboramphus antiquus & & & & & & & & & & \\
\hline 129 & カンムリカスス & Syn thliboranphus muizusune & & & & & & & & & & \\
\hline 130 & 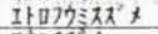 & Aethia cristatella & & & & & & & & & & \\
\hline 131 & $35 \equiv \pi x^{3} x$ & Aethia pusilla & & & & & & & & & & \\
\hline 132 & 外方 & Cerorhinca sonocerata & & & & & & & & & & \\
\hline 133 & Itr・in & Lunda cirrhata & & & & & & & & & & \\
\hline 134 & 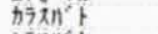 & Columba janthina & & & & & & & & & & \\
\hline 135 & รทำ & Streptopelia decaocto & & & & & & & & & & \\
\hline 136 & $\neq n^{\prime}$ & Streptopelia oriental is & 3 & & & & & & & 9 & 7 & \\
\hline 137 & $\neq n^{2}+$ & Chalcophaps indica & & & & & & & & & & \\
\hline 138 & 扸上 & Sphenurus sieboldii & & & & & & & & & & \\
\hline 139 & $x^{3}>n>3 n^{2}$ & Sphenurus formosae & & & & & & & & & & \\
\hline 140 & $y^{\prime} 214$ & Cuculus fugax & & & & & & & & & & \\
\hline 141 & h⿻丁𠃋㇒ & Cuculus canorus & & & & & & & & & & \\
\hline 142 & 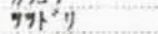 & Cuculus saturatus & & & & & & & & & & \\
\hline 113 & 朴朕元 & Cuculus pol iocephalus & & & & & & & & & & \\
\hline 144 & ร77ท0 & Ketupa blakistoni & & & & & & & & & & \\
\hline 145 & $157 \pi 7$ & Asio otus & & & & & & & & & 2 & \\
\hline 146 & 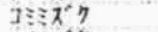 & As í flanneus & & & & & & & & 1 & & \\
\hline 147 & $\sin x$ & otus scops & & & & & & & & & & \\
\hline 148 & 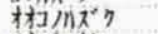 & Otus bakkanoena & & & & & & & & & & \\
\hline 149 & $7 n^{2} x^{\prime} \eta$ & Ninox scutulata & & 2 & & & & & & 1 & 1 & \\
\hline 150 & วク吹 & Strix uralensis & & & & & & & & 1 & 1 & \\
\hline
\end{tabular}




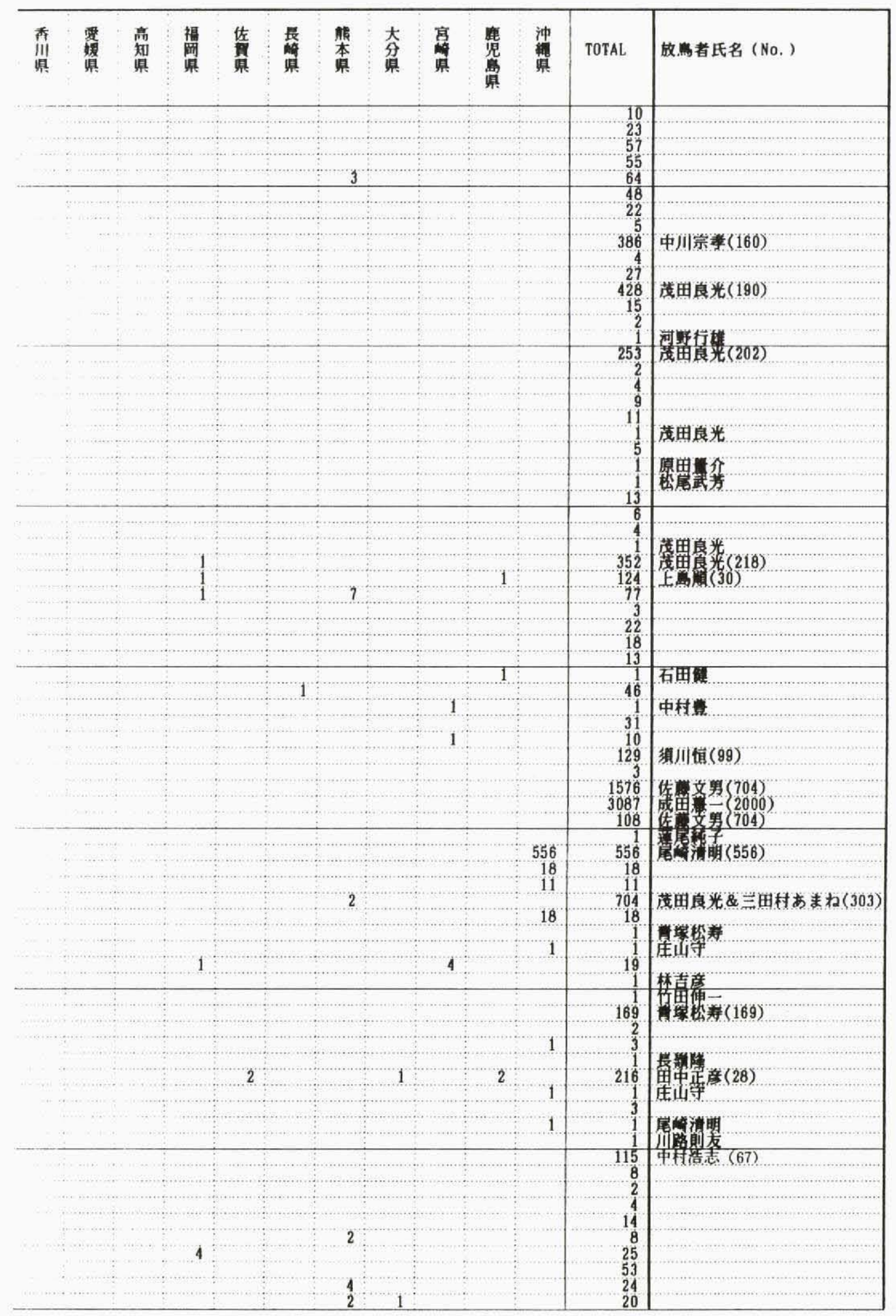




\begin{tabular}{|c|c|c|c|c|c|c|c|c|c|c|c|c|}
\hline & 㬐名 & 学名 & 耐 & $\begin{array}{l}\text { 岳 } \\
\text { 無 }\end{array}$ & $\begin{array}{l}\text { 晕 } \\
\text { 賮 }\end{array}$ & $\begin{array}{l}\text { 和 } \\
\text { 岸 } \\
\text { 嵔 }\end{array}$ & 焉 & $\begin{array}{l}\text { 岛 } \\
\text { 舆 }\end{array}$ & $\begin{array}{l}\text { 岡 } \\
\text { 真 }\end{array}$ & $\begin{array}{l}\text { 広 } \\
\text { 谧 }\end{array}$ & $\begin{array}{l}\text { 㟔 } \\
\text { 真 }\end{array}$ & 第 \\
\hline 151 & 可多 & Capriaulgus indicus & & & & & & & & & & \\
\hline 152 & 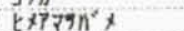 & Apus affinis & & & & & & & & & & \\
\hline 153 & 赌: & Ceryle lugubris & & & & & & & & & & \\
\hline 154 & 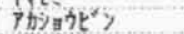 & Halcy on coronanda & & & & & & & & & & \\
\hline 155 & thot & Alcedo at this & 13 & 1 & & & 1 & & & 3 & 1 & \\
\hline 156 & 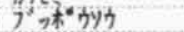 & Eurys tonus orientalis & & 3 & & & & & & & & \\
\hline 157 & PIIX1 & Jynx torquilla & 1 & & & 1 & & 1 & & 2 & & \\
\hline 158 & $f+y^{2}=$ & Picus awokera & & & & & & & & 3 & & \\
\hline 159 & $77)^{\prime} 5$ & Picus canus & & & & & & & & & & \\
\hline 160 & $734 \times \frac{1}{3}$ & Dryocopus artius & & & & & & & & & & \\
\hline 161 & $76+\frac{1}{5}$ & Dendrocopos ajor & & & & & & & & 2 & & \\
\hline 162 & 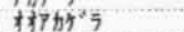 & Dendrocopos leucotos & & & & & & & & & & \\
\hline 163 & $27+54=5$ & Dendrocopos inor & & & & & & & & & & \\
\hline 164 & $7 \gamma^{2} 5$ & Dendrocopos kizuki & & & & 3 & & & 1 & 10 & 7 & 1 \\
\hline 165 & 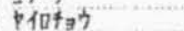 & Pitta brachyura & & & & & & & & & & \\
\hline 166 & $\left(e n^{2}\right)^{3}$ & Alauda arvensis & & & & & & & & & 1 & \\
\hline 167 & 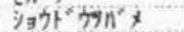 & Riparia riparia & & & & & & & & & 10 & \\
\hline 168 & $9 n^{2} \times$ & Hirundo rustica & 880 & 14 & & 27 & 194 & 2 & 5 & 6 & 1574 & \\
\hline 169 & בรTthy $x$ & Hirundo daurica & & & & & & & & 5 & 1 & \\
\hline 170 & $179 n^{\circ} \times$ & Delichon urbica & & 90 & & & & & & & & \\
\hline 171 & 何拉 & Dendronanthus indicus & & & & & & & & & & \\
\hline 172 & $y x+b^{2} b \neq 1$ & Motacilla flava & & & & & & & & & & \\
\hline 173 & $\neq$ キ६キ1 & Hotacilla cinerea & & & & 1 & 1 & & & 1 & 1 & \\
\hline 174 & $n 7 t \neq v 1$ & Motacilla alba & & & & & & & & & & \\
\hline 175 & $t 7^{3} \quad u t \neq v 1$ & Motacilla grandis & & & & & 6 & & & 1 & 1 & \\
\hline 176 & $\exists-n \rightarrow n \cdot r^{\prime} \cdot x^{\prime} 1$ & Anthus trivialis & & & & & & & & & & \\
\hline 177 & $t^{2}=z_{1} 1$ & Anthus hodgsoni & 19 & & & & & & & 2 & & \\
\hline 178 & $9 \mathrm{kn} \|^{3}$ & Anthus spinolet ta & & & & & & 1 & & 1 & & \\
\hline 179 & 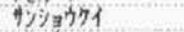 & Pericrocotus divaricatus & & & & & & & & & & \\
\hline 180 & 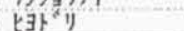 & Hypsipetes anaurotis & 36 & & 1 & 28 & 1 & 2 & 1 & 41 & 45 & 8 \\
\hline 181 & $t x^{2}$ & Lanius bucephalus & 17 & 8 & & 11 & 3 & 6 & & 9 & 21 & 8 \\
\hline 182 & phfex & Lanius cristatus & & & & & & & & & & \\
\hline 183 & $\neq \vee \forall *+\eta$ & Bombycilla garrulus & & & & & & & & & & \\
\hline 184 & 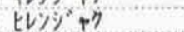 & Bonbycilla japonica & & & & & & & & & 2 & \\
\hline 185 & 加が & Cinclus pallasii & & & & & & & & & 8 & \\
\hline 186 & 洲角 & Troglodytes troglodytes & 1 & 1 & & & & & & 10 & 3 & \\
\hline 187 & 17ヒ片り & Prunella callaris & & & & & & & & & & \\
\hline 188 & 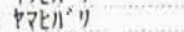 & Prunella montanella & & & & & & & & & & \\
\hline 189 & カヤククン・ & Prunella rubida & 1 & & & & & & & & & \\
\hline 190 & 간다 & Erithacus akahige & & & & & & 1 & & & & \\
\hline 191 & 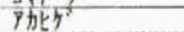 & Erithacus komadori & & & & & & & & & & \\
\hline 192 & 约文 & Erithacus sibilans & & & & & & & & & & \\
\hline 193 & I & Erithacus calliope & & & & & & 26 & & 7 & 5 & \\
\hline 194 & 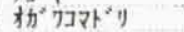 & Erithacus svecicus & & & & & & 1 & & & & \\
\hline 195 & JN) & Erithacus cyane & & & & & & 2 & & 13 & 1 & \\
\hline 196 & 牝妹 & Tarsiger cyanurus & 6 & 9 & 1 & 2 & & 5 & & 20 & 8 & \\
\hline 197 & $\because$ 旅多丰 & Phoenicurus auroreus & 4 & & & 3 & & 3 & & 13 & 22 & 2 \\
\hline 198 & 北多多 & Saxicola torguata & & & & 1 & 3 & 15 & & 8 & 3 & \\
\hline 199 & 化羽将 & Monticola solitarius & & & & & & & & & 1 & \\
\hline 200 & 㭅品 & Turdus sibiricus & & 1 & & & & & & 1 & & \\
\hline 201 & $1597^{5} \leqslant$ & Turdus dauna & 2 & & & 1 & & & & 4 & 3 & \\
\hline 20 & t57加 & furdus hortulorue & & & & & & & & & & \\
\hline 20. & ทัท & furdus cardis & 1 & & & & 2 & & & 8 & & \\
\hline 20 & $7 \tan 5$ & Turdus chrysolaus & 2 & & & & & i & 1 & & & \\
\hline 20 & $7 f 3,3$ & turdus celaenops & & & & & & & & & & \\
\hline & ; & Turdus pallidus & 21 & 8 & 5 & 18 & 2 & 6 & 2 & 73 & 39 & 6 \\
\hline 20 & $7:++i^{2}+1$ & Turdus obscurus & & & & & & & & 1 & & \\
\hline 208 & $97 \vdots$ & Turdus nauanni & 15 & & & 6 & & & & 13 & 15 & 2 \\
\hline 20 & $64 \times 5$ & Panurus biar icus & & & & & & & & & & \\
\hline & $87.4 x$ & Cettia squaneiceps & 2 & & & & 2 & & & 16 & 1 & \\
\hline 211 & 3712 & Cettia diphone & 36 & $1 \frac{1}{13}$ & 5 & 24 & & 24 & $\frac{1}{2}$ & 43 & $43^{3}$ & \\
\hline 212 & 材斩 & Hegalurus pryeri & & & & & & & & & & \\
\hline 213 & I & Locustella fasciolata & & & & & & & & 1 & & \\
\hline 214 & VPt广 $=x^{n}$ & Locustella ochotens is & & & & & 17 & $290^{\circ}$ & & & 1 & \\
\hline 215 & 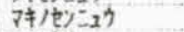 & Locustella lanceolata & & & & & & & & & & \\
\hline & ココンキ1 & Acrocephalus bistrigiceps & & & & & 27 & 570 & & 4 & 3 & \\
\hline 21 & 狇洋划 & Acrocephalus arundinaceus & 101 & 5 & & 8 & 25 & 58 & 1 & 13 & 98 & \\
\hline & fln:m1 & Phylloscopus & & & & & & & & & & \\
\hline 219 & $i=t \rightarrow \pi$ & Phy 11 oscopus fuscatus & & & & & & & & & & \\
\hline & A5가수 & Phylloscopus schwarzi & & & & & & & & & & \\
\hline & F71hing & Phylloscopus inornatus & & & & & & & & & & \\
\hline 222 & 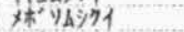 & Phylloscopus borealis & 4 & 3 & 1 & 8 & & 5 & 2 & 7 & 8 & \\
\hline 223 & IY В Вท1 & Phylloscopus tenellipes & & i & & & & & & & 3 & \\
\hline 224 & 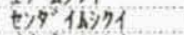 & Phylloscopus occipitalis & & i & & & & & & 1 & 3 & \\
\hline & & Phylloscopus ijinae & & & & & & & & & & \\
\hline
\end{tabular}




\begin{tabular}{|c|c|c|c|c|c|c|c|c|c|c|c|c|}
\hline 乔 & 要 & $\begin{array}{l}\text { 高 } \\
\text { 策 }\end{array}$ & 悬 & 售 & 長 & 䏺 & 睝 & 亮 & 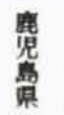 & 染 & TOTAL & 放鳌氏名（No.） \\
\hline & & & & & 2 & & & & & & $\begin{array}{l}9 \\
1\end{array}$ & 近献多美学 \\
\hline & & & & & & & & & & 10 & 3 & \\
\hline & 7 & & 2 & & & & & & 1 & 18 & 125 & 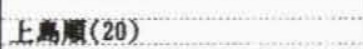 \\
\hline & & & & & & & & & 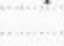 & & 3 & \\
\hline & & & & & & & & & & & $\begin{array}{l}70 \\
20\end{array}$ & \\
\hline & & & & & & & & & & & 8 & \\
\hline & & & 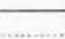 & & & & & & 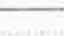 & & $14 \frac{1}{5}$ & 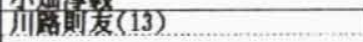 \\
\hline & & & $\ldots$ & & & & & & & & 8 & \\
\hline & & & ... & & & & & & 1 & 1 & $110^{\circ}$ & 若田能(15) \\
\hline & & & & & & & & & & & $\frac{1}{14}$ & 你田伸一 \\
\hline & & & & & & & & & 1 & & 1068 & 圾和荟 $(462)$ \\
\hline & & & 121 & 7 & 30 & 8 & 3 & 25 & 43 & & $\begin{array}{r}7457 \\
29\end{array}$ & 政 \\
\hline & & & 900 & & & & & & & & 1074 & 武华文(146) \\
\hline & & & 1 & & $?$ & & & $\ldots$ & ........ & & & 交我茟三 \\
\hline & & & & & 2 & 1 & & & 1 & 1 & $70^{\circ}$ & \\
\hline & & & 44 & & & & & & & & $\begin{array}{r}1797 \\
178\end{array}$ & 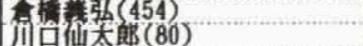 \\
\hline & & & & & & & & & & & & 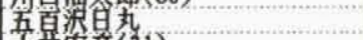 \\
\hline & & & $\begin{array}{r}26 \\
4\end{array}$ & & $\begin{array}{l}3 \\
1\end{array}$ & 2 & & & & & $\begin{array}{r}248 \\
83\end{array}$ & 土井安虚(31) \\
\hline & & & & & & & & & & & $10^{3}$. & \\
\hline & $\frac{1}{5}$ & & $\frac{13}{2}$ & & $\frac{5}{8}$ & 4 & 1 & & $\frac{29}{8}$ & 36 & $\frac{1166}{1088}$ & 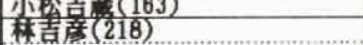 \\
\hline & & & & & & & & & & & 28 & \\
\hline & & & & & & & & & & & 40 & .......... \\
\hline & & & & & …. & $\ldots \ldots . .$. & & $\ldots . .$. & & & 17 & \\
\hline & & & 3 & & & & & & & & $\begin{array}{r}155 \\
24\end{array}$ & 株吉庶(23) \\
\hline & & & & & $\ldots . .$. & & & $\ldots .$. & & & 4 & . \\
\hline & & & 1 & & & & & & & & 50 & 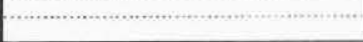 \\
\hline & $\ldots$ & $=\ldots$ & $\ldots$ & $\ldots \ldots . .$. & 1 & …… & $\ldots$ & ....... & 3 & & 3 & \\
\hline & 1 & & 5 & & $\frac{1}{3}$ & 3 & & & 1 & & $1990^{\circ}$ & 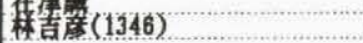 \\
\hline & & & 5 & & 3 & & & & & & $13^{2}$ & 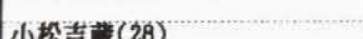 \\
\hline & & & 8 & & 1 & 1 & & $\ldots$ & 1 & & $\begin{array}{l}138 \\
1287\end{array}$ & 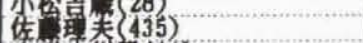 \\
\hline & & & 3 & & $i$ & 3 & & & 1 & & 409 & 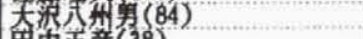 \\
\hline & & & & & 1 & & & & 1 & & 150 & 田中正廉(38) \\
\hline & & & 1 & & 1 & & & & & & 37 & 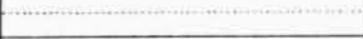 \\
\hline & & & 1 & $\ldots . . .$. & $\ldots . .$. & & $\ldots$ & $\ldots+\ldots$ & 1 & & 84 & \\
\hline & & & 2 & & 1 & & & 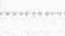 & 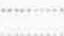 & & 950 & 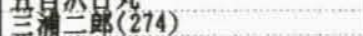 \\
\hline & & & 1 & & & & & & & & 1584 & 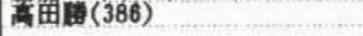 \\
\hline & & & 24 & & 8 & 1 & & & 20 & 5 & 1440 & 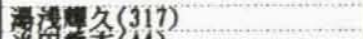 \\
\hline & 2 & & 3 & 1 & 3 & 1 & & & 1 & & 770 & 出岗量 $(116)$ \\
\hline & & & 5 & & 1 & & & & & & 288 & 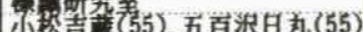 \\
\hline & 3 & & 7 & $\ldots$ & 8 & 1 & & $\ldots$ & 15 & 2 & 3438 & 㚣鎬签 \\
\hline & & & & & & & & & & & $\begin{array}{r}151 \\
45\end{array}$ & 䇅田良光 \&三田村あまね(116) \\
\hline & & & & 2 & 1 & & & & & & 425 & 土居克夫(253) \\
\hline & & & 6 & & 1 & & & & & & 1342 & 土居克夫(554) \\
\hline & 2 & & & & & & & & & & $1690^{\circ}-1-5$ & 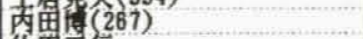 \\
\hline & & & & & & & & & & & 3 & 作田证:何 \\
\hline & & & & & & & & & & & i & 囱品焦 \\
\hline & 1 & & & & 13 & & & & 1 & 1 & 667 & 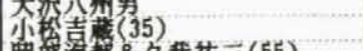 \\
\hline & & & $\begin{array}{l}59 \\
42\end{array}$ & & 4 & & & & & & $\begin{array}{l}218 \\
275\end{array}$ & 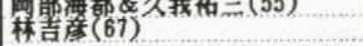 \\
\hline & & & & & & & & & & & & \\
\hline
\end{tabular}









\begin{tabular}{|c|c|c|c|c|c|c|c|c|c|c|c|c|}
\hline $\begin{array}{l}\text { 梖 } \\
\text { 瞋 }\end{array}$ & $\begin{array}{l}\text { 爱 } \\
\text { 㫷 }\end{array}$ & $\begin{array}{l}\text { 离 } \\
\text { 筧 }\end{array}$ & $\begin{array}{l}\text { 眮 } \\
\text { 累 }\end{array}$ & $\begin{array}{l}\text { 佐 } \\
\text { 集 }\end{array}$ & 長 & 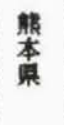 & 茐 & 蒠 & $\begin{array}{l}\text { 鬼 } \\
\text { 番 }\end{array}$ & 沖 & TOTAL & 故鳥者氏名（No.） \\
\hline & 2 & & 2 & & 19 & 2 & & & 6 & & $\begin{array}{r}109 \\
392 \\
\end{array}$ & 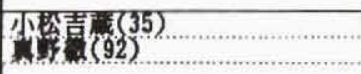 \\
\hline & & & $\begin{array}{r}1 \\
18\end{array}$ & & 1 & & & 1 & 1 & 15 & -427 & 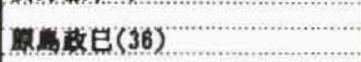 \\
\hline & & & & & & & & & 2 & & & \\
\hline & 1 & & 17 & & 2 & & & & 1 & $\cdots$ & $\begin{array}{r}233 \\
-4\end{array}$ & 尔稂䓀(52). \\
\hline & & & & & & & & & & & $\begin{array}{r}11 \\
8\end{array}$ & \\
\hline & & & 3 & 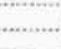 & & ant & & & & 5 & 80 & $\ln 20$ \\
\hline & 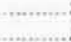 & & & & $\ldots \ldots . .$. & 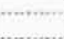 & & & 11 & & $\begin{array}{r}18 \\
860\end{array}$ & 山肉署(88) \\
\hline & & & 435 & 41 & 50 & 1 & & & 64 & & $\begin{array}{r}801 \\
\quad 450 \\
\end{array}$ & 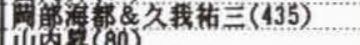 \\
\hline & & & & & & & & & ....... & ...... & 283 & W. \\
\hline & ….... & & & ........ & ........ & …….. & .... & ....... & $g$ & .......... & $\begin{array}{r}901 \\
408\end{array}$ & 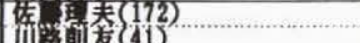 \\
\hline & & & 7 & & 19 & .... & $\ldots$ & & 6 & 11 & 5627 & 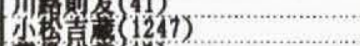 \\
\hline & & & & & & $\ldots \ldots$ & ... & …...... & & & $\begin{array}{r}139 \\
32\end{array}$ & 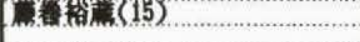 \\
\hline & 2 & & 31 & $\cdots \cdots . .$. & 1 & ......... & & $\ldots$ & 18 & 266 & 4077 & 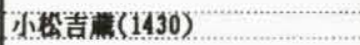 \\
\hline & & & & & & & & & & & $\begin{array}{r}5 \\
2\end{array}$ & \\
\hline & 35 & .... & 22 & 12 & 52 & 36 & & & 14 & & 2114 & 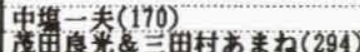 \\
\hline & 1 & & $\frac{2}{8}$ & 10 & 17 & 15 & & .... & 29 & $\cdots$ & $\begin{array}{r}8 \\
330^{6}\end{array}$ & 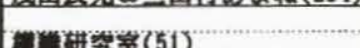 \\
\hline & & & 1 & 1 & 10 & & & & 69 & & $\begin{array}{r}50 \\
8\end{array}$ & Wholot \\
\hline & 2 & & 10 & 33 & 27 & 10 & $\cdots$ & & 3 & & $11806^{2}$ & 由井正魰 (1319) \\
\hline & & & 11 & & 1 & 3 & & & 4 & & $\begin{array}{r}426 \\
\end{array}$ & $(60)$ \\
\hline & 2 & & 3 & & & & & $\cdots$ & ......... & & 116 & 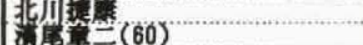 \\
\hline & 41 & & 9 & & 18 & 262 & & & 32 & & 27929 & 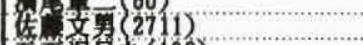 \\
\hline & & & $\frac{2}{1}$ & 1 & & & & & & & $\begin{array}{r}797 \\
5\end{array}$ & 五百泿目丸(132) \\
\hline & 16 & & 504 & 64 & 149 & 105 & & & 241 & & 13513 & 中壦和夫 (2373) \\
\hline & & & 10 & & & & & & & ... & $230^{2}$ & 小扮吉数(35) \\
\hline & 7 & & 39 & 13 & 35 & 4 & & & 1 & & $\begin{array}{r}1653 \\
-165\end{array}$ & (341) \\
\hline & & & 5 & & & & & & & & $\begin{array}{r}307 \\
5\end{array}$ & 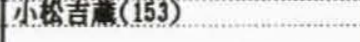 \\
\hline & & & & & & & & & & & $\quad 2$ & 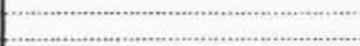 \\
\hline & & & & & & & & & & & $\begin{array}{r}86 \\
84\end{array}$ & - \\
\hline & 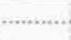 & & ......... & $\ldots \ldots .$. & $\ldots$ & .......... & & ${ }^{2}$ & ......... & ........ & 1233 & 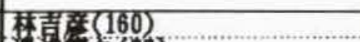 \\
\hline & & & & & & $x_{1}$ & & & w.. & .......... & $\begin{array}{l}360 \\
1\end{array}$ & 渭 $3(77)$ \\
\hline & & & & & & ............ & & $\cdots$ & 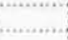 & c........ & & 恩渭量䬦(27) \\
\hline & & & 1 & & & & & & & & $\begin{array}{r}343 \\
258\end{array}$ & 玻和菜 $(104)$ \\
\hline & 5 & & 38 & 59 & 82 & 3 & & & 10 & & 3833 & 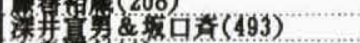 \\
\hline & & & & & & & & & & & 143 & 早眮䇢(111) \\
\hline & & & & & & & & & & & $\frac{827}{70}$ & 安雐虚戒(509) \\
\hline & $\ldots \ldots . .$. & & & 列 & $\ldots \ldots .$. & 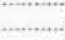 & 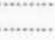 & & 1 & $\ldots$ & 1 & 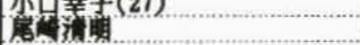 \\
\hline & & & & & & & & & 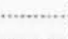 & 3 & $\begin{array}{l}63 \\
96\end{array}$ & \\
\hline & ........ & & & & & .. & & & & & 72 & \\
\hline & & & & & $\cdots 1$ & 3 & & & & ${ }_{0}$ & 13 & 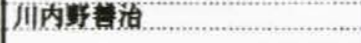 \\
\hline & & & & & & & & & & & 1 & 废居忠軎 \\
\hline & & & & & & & & & & & & \\
\hline & 136 & & 2569 & 246 & 580 & 518 & 7 & 35 & 613 & 1051 & 131598 & \\
\hline & 19 & & 63 & 13 & 43 & 29 & 5 & 6 & 45 & 28 & 290 & \\
\hline
\end{tabular}

